\title{
PENGARUH KARAKTERISTIK INDIVIDU TERHADAP KOMITMEN ORGANISASI PADA CV. BELIBIS PARIAMAN
}

\author{
Rozi Abdi, Febsri Susanti \\ Sekolah Tinggi Ilmu Ekonomi "KBP" \\ febsrisusanti@akbpstie.ac.id
}

\begin{abstract}
ABSTRAK
Penelitian ini dilakukan dengan tujuan untuk mengetahui pengaruh karakteristik individu terhadap komitmen organisasi pada CV. Belibis Pariaman. Tujuan penelitian adalah Untuk meneliti karakteristik individu terhadap komitmen organisasi. Teknik analisis data yang digunakan dalam penelitian ini adalah uji validitas, reliabilitas, uji normalitas, uji heteroskedastisitas, uji koefisien determinasi, uji t, uji regresi linear sederhana sehingga mendapatkan persamaan regresi $\mathrm{Y}=0,152+$ $0,897 \mathrm{X}$ dimana karakteristik individu $(\mathrm{X})$ berpengaruh positif dan signifikan terhadap komitmen organisasi (Y).
\end{abstract}

Kata kunci : Karakteristik Individu dan Komitmen Organisasi.

\section{PENDAHULUAN}

Organisasi merupakan tempat individu mendapatkan suatu rasa aman, status, penghargaan diri (selfesteem), keterikatan (affiliation) dan kekuasaan, sehingga keberadaan organisasi merupakan suatu wadah atas berbagai tujuan, harapan, dan kepentingan. Sekelompok orang mendirikan organisasi dengan suatu alasan bahwa organisasi akan dapat mencapai sesuatu yang tidak dapat dicapai secara peseorangan. Tujuan dan sasaran organisasi akan dapat dicapai lebih efisien dan efektif melalui tindakan tindakan yang dilakukan secara kolektif dan diselenggarakan dengan persetujuan bersama. Hampir semua organisasi menghendaki agar semua orang yang masuk dalam organisasi secara garis besar menganut nilai, sikap, dan tujuan yang sama.

Hal tesebut semata-mata untuk memelihara kesatuan dan kelangsungan organisasi. Sementara itu, individu dengan berbagai macam tujuan dan kepentingan masuk dalam organisasi dengan harapan mendapatkan suatu kepuasan, baik secara ekonomis maupun psikologis. Seandainya, keberadaan setiap individu dalam organisasi tidak sesuai dengan yang diharapkan, maka sebagian orang akan memilih untuk meninggalkan organisasi atau sejak permulaan sudah menghindari untuk memasukinya. Sehingga, untuk mengikat anggota organisasi diperlukan adanya 
keserasian tujuan dan kepentingan. Hal tersebut adalah penting untuk mempermudah proses pengelolaan organisasi.

Komitmen organisasi dimana organisasi mempunyai wewenang dalam hal ini organisasi mempunyai wewenang dan tanggung jawab kepada karyawan dan sebaliknya karyawan perlu memiliki komitmen untuk meningkatkan kompetensi diri, dalam sebuah komitmen organisasi secara karakteristik personalnya yaitu yang mencakup usia, masa jabatan, motif berprestasi, ras dan faktor kepribadian.

CV. Belibis Pariaman merupakan sebuah badan usaha yang bergerak dalam bidang pengadaan alat alat berat dan konstruksi yang bekerja sama dengan dinas pekerjaan umum kabupaten Padang Pariaman maupun dinas pekerjaan umum kabupaten lain, badan usaha ini telah lama bergerak dalam bidang konstruksi yang sudah berjalan selama 6 tahun yang mempunyai lebih kurang karyawan 56 orang.

Dalam sebuah organisasi usia merupakan hal yang sangat penting dalam menjalankan organisasi, dimana karakteristik seorang karyawan dapat dilihat dari usia mereka, dalam penelitian ini yang terjadi pada CV. Belibis Pariaman dimana usia karyawan yang bekerja rata - rata 35 tahun dimana usia termuda adalah 28 tahun dan usia tertua 45 tahun. Dilihat dari karakter mereka usia muda lebih cendrung lalai dan sering mengabaikan pekerjaan namun sebaliknya usia yang lebih tua lebih cendrung konsisten terhadap organisasi ini dapat dibuktikan, ini sesuai dengan teori yaitu karyawan yang lebih tua lebih tua dan lebih lama bekerja secara konsisten menunjukkan nilai komitmen yang tinggi ( Steers, 1988 ).

Jenis kelamin merupakan faktor dari komitmen organisasi dimana jenis kelamin mempunyai pengaruh terhadap berlangsungnya organisasi, pengamatan yang dilakukan pada CV Belibis Pariaman dimana wanita lebih sedikit dibandingkan laki laki, karena CV. Belibis Pariaman bergerak dalam bidang pengadaan alat alat berat dan konstruksi pembangunan yang bekerja sama dengan dinas pekerjaan umum kabupaten Padang Pariaman, dilihat dari jenis kelamin banyak yang dipekerjakan laki laki dibandingkan wanita, karna sifat dari karakteristik pekerjaan yang berat. Sedangkan wanita banayak dikerjakan sebagai administrasi dan mengelola keuangan, hal ini menunjukkkan bahwasanya seorang wanita lebih dipercaya dibidang administrasi dan keuangan, namaun sebaliknya laki laki banayak ditugaskan dibagian lapangan, pengerjaan proyek dan pengawasan proyek.

Pengerjaan proyek yang sangat sulit dan membutuhkan waktu lama merupakan tantangan utama pada CV. Belibis Pariaman, dimana proyek ini menghabiskan waktu dan tenaga kerja yang banyak, tentu saja untuk mencapai proyek selesai pada jadwal yang telah ditentukan, dibutuhkan kekompakan dan kerja sama team. Hal ini sangat ditentukan dari karakteristik individu masing masing karyawan untuk mencapai tujuan organisasi yang sesuai dengan komitmen organisasi yang telah diterapkan, dalam melakukan pengamatan kelapangan secara langsung CV. Belibis Pariaman mampu mengerjakan proyek yang telah diterima dari dinas pekerjaan umum kabupaten Padang Pariaman.

CV. Belibis Pariaman juga memberikan hak dan tanggung jawab kepada karyawannya yakni dengan memberikan gaji yang sesuai dengan ketentuan UMR 
dikabupaten Padang Pariaman serta memberikan tunjangan tunjangan lain kepada karyawan, sistem yang dipakai dalam perekrutan karyawan terbagi atas dua, yaitu karyawan kontrak dan karyawan harian lepas dimana karyawan kontrak dipekerjakan dibagian administrasi, keuangan, mandor dan bagian pengawasan, sedangkan untuk karyawan harian lepas dipekerjakan sebagai kuli atau pekerja buruh kasar. Berikut ini data mengenai jumlah karyawan CV Bilibis Pariaman berdasarkan jenis kelamin dan usia sebagai berikut :

Tabel 1

Data jumlah karyawan berdasarkan usia kerja dan masa kerja

\begin{tabular}{|c|c|c|c|c|c|c|c|}
\hline \multirow{2}{*}{$\begin{array}{c}\text { Jenis } \\
\text { Kelamin }\end{array}$} & \multirow[t]{2}{*}{ Jumlah } & \multicolumn{3}{|c|}{ Jumlah Berdasarkan usia } & \multicolumn{3}{|c|}{ Masa kerja } \\
\hline & & $\begin{array}{c}\text { 28-35 } \\
\text { Thn }\end{array}$ & $\begin{array}{c}\text { 36-40 } \\
\text { Thn }\end{array}$ & $\begin{array}{c}\text { 41-45 } \\
\text { Thn }\end{array}$ & $<2$ & $3-4$ & $5-6$ \\
\hline Laki-laki & 49 & 15 & 16 & 18 & 16 & 18 & 15 \\
\hline Perempuan & 7 & 1 & 3 & 3 & 1 & 4 & 2 \\
\hline Total & 56 & 16 & 19 & 21 & 17 & 22 & 17 \\
\hline
\end{tabular}

Sumber : CV. Belibis Pariaman

Berdasarkan tabel diatas dapat kita lihat jumlah karyawan pada usia 41-45 tahun merupakan jumlah tertinggi dan jumlah karyawan berdasarkan masa kerja tertinggi dibawah 4 tahun. Hal ini dikhawatirkan dapat menjadi penyebab kurangnya loyalitas karyawan berdasarkan pendapat ahli yang menyatakan bahwa karyawan yang berusia lebih tua cenderung lebih mempunyai rasa keterikatan atau komitmen pada organisasi dibandingkan dengan yang berusia muda sehingga meningkatkan loyalitas mereka pada organisasi dan masa kerja yang lama akan cenderung membuat seorang pegawai lebih merasa betah dalam suatu organisasi.

Dari latar belakang masalah di atas, maka yang menjadi rumusan masalah pokok dalam penelitian ini adalah seberapa besarkah pengaruh karakteristik individu terhadap komitmen organisasi pegawai pada CV. Belibis Pariaman?

Tujuan penelitian ini adalah untuk mengetahui seberapa besarkah pengaruh karakteristik individu terhadap komitmen organisasi pada CV. Belibis Pariaman.

Manajemen sumber daya manusia adalah ilmu dan seni mengatur hubungan dan peranan tenaga kerja agar efektif dan efisien membantu terwujudnya tujuan perusahaan, karyawan dan masyarakat ( Hasibuan 2000 )

Siagian (2008) menyatakan bahwa, Karakteristik biografikal (individu) dapat dilihat dari umur, jenis kelamin, status perkawinan, jumlah tanggungan dan masa kerja . Menurut Morrow menyatakan bahwa, komitmen organisasi dipengaruhi oleh karakter personal (individu) yang mencakup usia, masa kerja, pendidikan dan jenis kelamin (Prayitno, 2005).

Pengaruh Karakteristik Individu terhadap Komitmen Organisasi

1. Pengaruh Usia terhadap Komitmen Organisasi

Semakin tua umur seseorang akan semakin trampil dalam melaksanakan tugas, semakin kecil tingkat kesalahannya dalam melaksanakan pekerjaannya. Siagian (2008) mengemukakan, Berkaitan dengan tingkat absensi, kehadiran 
seseorang dalam pekerjaannya tidak merupakan jaminan, artinya semakin tua tidak dapat dijadikan jaminan tingkat kehadirannya semakin tinggi.

2. Pengaruh Jenis Kelamin terhadap Komitmen Organisasi

Greenberg dan Baron (2003) menyatakan bahwa, Jenis kelamin wanita memiliki komitmen yang lebih rendah dari pada pria yang disebabkan adanya diskriminasi di tempat kerja yang menganggap kemampuan wanita tidak sama dengan pria sehingga kebanyakan wanita memperoleh kedudukan atau posisi yang lebih rendah dan kurang terlibat dalam masalah-masalah organisasi .

3. Pengaruh Status Perkawinan terhadap Komitmen Organisasi

Berkaitan dengan komitmen organisasi, ada pengaruh positif antara status perkawinan seseorang dengan komitmennya terhadap organisasi. Dyne dan Graham (2005).

4. Pengaruh Masa Kerja terhadap Komitmen Organisasi

Masa kerja dalam penelitian ini diartikan sebagai lamanya pegawai bekerja dalam organisasi atau perusahaan saat ini, tidak termasuk lamanya bekerja pada perusahaan lain sebelumnya bagi pegawai yang telah pernah bekerja di perusahaan lain.

5. Pengaruh Jumlah Tanggungan terhadap Komitmen Organisasi

Salah faktor yang mempengaruhi komitmen organisasi adalah jumlah tanggungan seseorang. Menurut Siagian (2008) menyatakan bahwa, Semakin besar jumlah tanggungan seseorang maka akan semakin besar komitmennya terhadap organisasi.

\section{METODE PENELITIAN}

Metode penelitian pada dasarnya merupakan cara ilmiah untuk mendapatkan data dengan tujuan dan kegunaan tertentu. Berdasarkan hal tersebut terdapat empat kunci yang perlu diperhatikan yaitu, cara ilmiah, data, tujuan, dan kegunaan. Cara ilmiah berarti kegiatan itu didasarkan pada ciri - ciri keilmuan, yaitu rasional, empiris, dan sistematis. Rasional berarti kegiatannya itu dilakukan dengan cara - cara yang masuk akal, sehingga terjangkau oleh penalaran manusia. Empiris berarti cara cara yang dilakukan itu dapat diamati oleh indera manusia, sehingga orang lebih dapat mengamati dan mengetahui cara - cara yang digunakan. Sistematis artinya proses yang digunakan dalam penelitian itu menggunakan langkah - langkah tertentu yang bersifat logis ( Sugiyono 2012 )

Dalam permasalahan yang akan diteliti pada penelitian ini adalah penelitian kuantitatif yang bersifat kausal, yaitu hubungan yang bersifat sebab akibat. Jadi disini ada variable independen ( variabel yang memengaruhi ) dan variabel dependen ( dipengaruhi ) Sugiyono 2012. Pada penelitian ini, ingin melihat seberapa besarkah pengaruh karakteristik individu dan komitmen organisasi pada CV Belibis Pariaman.

Untuk memperoleh data yang dikehendaki sesuai dikehendaki sesuai dengan permasalahan dalam penelitian ini, maka penulis menggunakan metode - metode Wawancara, Kuisioner dan observasi. 


\section{HASIL DAN PEMBAHASAN}

Berdasarkan hasil pengujian hipotesis, ditemukan bahwa variabel karakteristik individu berpengaruh positif dan signifikan terhadap komitmen organisasi, hal ini dapat dilihat melalui hasil nilai signifikan uji $t$ sebesar $0,000<\alpha=0,05$. Ini berarti ada perngaruh karakteristik individu terhadap komitmen organisasi.

Besaran koefisien regresi variabel karakteristik individu adalah 0,897 yang artinya apabila karakteristik individu karyawan CV. Belibis Pariaman meningkat maka komitmen organisasi karyawan juga meningkat. Penelitian mendukung teori dari Robbins (2015) dalam jurnal Eka Rosita Widya Sariningtyas (2016) karakteristik individu merupakan ciri - ciri tertentu yang membedakannya dengan orang lain yang meliputi, usia, jenis kelamin, status perkawinan, sikap dan tingkat kemampuan akan mempengaruhi perilaku dalam organisasi. Penelitian ini sejalan dengan penelitian yang dilakukan oleh Kristian SW Nugraha, Acep Edison (2014), Ngurah Agung Guruh Saputra (2015), dan Eka Rosita Widya Sariningtyas (2016) dengan hasil penelitian karakteristik individu berpengaruh positif dan signifikan terhadap komitmen organisasi. Karakteristik individu yang ada dalam CV. Belibis pariaman dari informasi ke lapangan dimana karyawan CV. Belibis Pariaman disana banyak karyawan laki - laki dari pada perempuan, ini artinya bahwasan nya laki laki disana mempunyai tanggung jawab serta mereka yang telah berkeluarga cenderung untuk bertahan atau ingin tetap bekerja di CV. Belibis Pariaman. jurnal Eka Rosita Widya Sariningtyas (2016) mengemukakan karyawan yang memiliki komitmen tinggi cenderung menunjukan keterlibatan yang tinggi yang diwujudkan dalam bentuk sikap dan perilaku, disamping itu mereka kemungkinan untuk tetap bertahan diperusahaan juga lebih tinggi dari pada karyawan yang tidak memiliki komitmen.

\section{KESIMPULAN}

Berdasarkan hasil penelitian yang telah dilakukan di CV. Belibis Pariaman dan hasil pembahasannya maka disimpulkan bahwa karakteristik individu berpengaruh positif dan signifikan terhadap komitmen organisasi, hal ini dapat dilihat melalui hasil nilai signifikan uji $\mathrm{t}$ sebesar $0,000<\alpha=0,05$. Ini berarti ada perngaruh karakteristik individu terhadap komitmen organisasi danbesaran koefisien regresi variabel karakteristik individu adalah 0,897 yang artinya apabila karakteristik individu karyawan CV. Belibis Pariaman meningkat maka komitmen organisasi karyawan juga meningkat.

Saran diharapkan kepada peneliti selanjutnya untuk dapat menggunakan penelitian ini sebagai referensi yang nantinya akan memberikan perbandingan dalam melakukan penelitian pada bidang yang sama dimasa yang akan dating, bagi peneliti agar dapat mengkaji lebih dalam wawasan dan pendalaman pengetahuan dalam manajemen sumber daya manusia khususnya yang berkaitan dengan Pengaruh karakteristik individu terhadap komitmen organisasi. diharapkan penelitian ini dapat menjadi referensi untuk mengambil suatu keputusan pada CV. Belibis Pariaman 
terutama yang berkaitan dengan Pengaruh karakteristik individu terhadap komitmen organisasi.

\section{DAFTAR PUSTAKA}

Aziz, N. (2019). Pengaruh Lingkungan Kerja Terhadap Kinerja Yang Dimediasi Oleh Motivasi Kerja Karyawan Rocky Plaza Hotel Padang. https://doi.org/10.17605/OSF.IO/E4C59

Eka Rosita Widya sariningtyas dan Sulistiani, 2016, jurnal analisis karakteristik individu dan motivasi intrinsikterhadap komitmen organisasi dengan kepuasa kerja sebagai variabel intervenig studi pada PDAM Tirta muia Kabupaten Temalang, Universitas 17 Agustus 1945 Semarang.

Fendi, Z., \& Susanti, F. (2018). Pengaruh Kepuasan Kerja Terhadap Turnover Intention Dengan Komitmen Organisasi Sebagai Variabel Intervening Pada CV. Belibis Pariaman. https://doi.org/10.31227/osf.io/wumgX

Krietner, R. \& Kinicki, A. 2005.Perilaku Organisasi Terjemahan oleh Erly Suandy.Organizational Behavior. 2000.Edisi 5. Jakarta : Salemba Empat.

Kristian SW nugraha dan Acep edison, 2014, Jurnal karakteristik individu dan kecerdasan emosional pemimpin pengaruhnya terhadap komitmen organisasi da OCB pada karyawan PTPN XII kebun mumbul, Fakultas bisnis dan manajemen, universitas Widya Tama.

Luthans, Fred. 2006. Perilaku Organisasi, edisi 10. Yogyakarta: Penerbit Andi,.

Mathis, RL dan Jackson, J.H. 2001. Manajemen Sumber Daya Manusia. Terjemahan oleh Jimmy Sadeli dan Bayu Prawira Hie. Jakarta: PT. Salemba Empat.

Mayliza, R. (2019). Pengaruh Keadilan Organisasional Terhadap Kepuasan Kerja Karyawan Bank Nagari Cabang Utama Padang. https://doi.org/10.17605/OSF.IO/ZB928

Nawang Retno Dwiningrum, 2010, Jurna Pengaruh karakteristik personal dan karakteristik pekerjaan terhadap komitmen organisasi ( studi kasus pada poiteknik negeri balik papan.

Nitisemito, Alex S. 2001. Manajemen Personalia. Ghalia Indonesia, Jakarta.

Ngurah Agung Guruh Saputra, 2015, Jurnal Pengaruh karakteristik Individu terhadap Komitmen Organisasi karyawan Aditya Beach Resort Lovina Singaraja 
tahun 2014, Jurusan Pendidikan Ekonomi, Universitas Pendidikan Ganesha Singaraja.

Pangabean, M. S. 2004. Komitmen Organisasi Sebagai Mediator Variabel Bagi Pengaruh Kepuasan Kerja Terhadap Keinginan Untuk Berpindah Kerja.Jurnal Bisnis dan Akuntansi.Vol. 6.Tersedia pada http://jurnalonline. um.ac.id/.../artikel/pdf

Robbins. 1996. Perilaku Organisasi. Jakarta: PT Prenhallindo.

Robbins, Stephen P. 2001. Perilaku Organisasi.Terjemahan oleh Alexander Sindoro.Organizational Behavior.1996. Jakarta: PT Prenhallindo.

Robbins. 2003. Perilaku Organisasi. Konsep,Kontroversi, dan Aplikasi.Jilid.Jakarta: PT. Indeks Kelompok Gramedia.

Robbins 2006. Perilaku Organisasi. Edisi 12. Jakarta: Salemba Empat.

Sugiyono. 2012. Metode Penelitian Kuantitatif Kualitatif dan R \& D. Bandung: Alfabeta.

Sugiyono. 2013. Metode Penelitian Kuantitatif Kualitatif dan R \& D. Bandung: 